Review

\title{
Epidemiological Investigations of Infectious Diseases among Mobile Populations at the University Hospital Institute Mediterranean Infection in Marseille, France
}

\author{
Thi Loi Dao ${ }^{1,2,3}$, Van Thuan Hoang ${ }^{1,2,3,(\mathbb{D})}$, Tran Duc Anh Ly $y^{1,2,(\mathbb{D})}$, Ndiaw Goumballa ${ }^{1,2}$, Philippe Gautret ${ }^{1,2, *}, \mathbb{C}$ \\ ${ }^{1}$ Aix Marseille Univ, IRD, AP-HM, SSA, VITROME, France

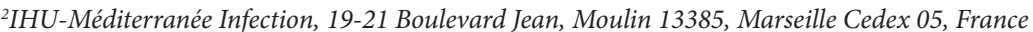 \\ ${ }^{3}$ Thai Binh University of Medicine and Pharmacy, Thai Binh, Vietnam
}

\author{
ARTICLE INFO \\ Article History \\ Received 17 October 2020 \\ Accepted 21 May 2021 \\ Keywords \\ Respiratory tract infections \\ gastrointestinal infections \\ antibiotic-resistant bacteria \\ real-time PCR \\ mass gatherings \\ international travelers \\ precarious populations
}

\begin{abstract}
We review the most recent work conducted by our group on the circulation of infectious agents in mobile populations, including pilgrims participating in the Hajj (Mecca, Saudi Arabia) and the Grand Magal of Touba (Senegal) pilgrimages, homeless people, and medical students participating in an elective abroad. Using a similar epidemiological study design with standardized questionnaires and molecular assays allows comparison of different populations of travelers. The main infectious pathogens and antibiotic resistance genes linked to travel were identified in certain specific populations of travelers, as well as in a group of homeless migrant people in Marseille. The role of several risk factors has also been demonstrated, allowing identifying individuals at increased risk of disease or pathogen carriage on which to base targeted preventive measures. Such results, together with those obtained through international surveillance networks allow better description of the epidemiology of travel-associated infectious diseases.
\end{abstract}

(C) 2021 The Authors. Published by Atlantis Press International B.V. This is an open access article distributed under the CC BY-NC 4.0 license (http://creativecommons.org/licenses/by-nc/4.0/).

\section{INTRODUCTION}

Successive waves of migrants have settled in Marseille, originating mostly from Algeria, Armenia, Corsica, Lebanon, Morocco, Tunisia, Portugal, the Comoros and Italy, making the city population one of the most cosmopolitan in France with around 1.5 million inhabitants. Marseille is also an international port and the seat of several large international companies using expatriate workers worldwide, and the city has a large university campus hosting student from various countries of origin, part of whom participate in an elective abroad. To answer the population needs, the Institut Méditerranée Infection (Mediterranean Infection Institute) has a travel clinic where more than 7000 international travelers [mostly tourists, business travelers and students and migrants Visiting their Friends and Relatives (VFR) in their country of origin] are seen yearly for pre-travel advice and vaccinations. In addition, the Institute coordinates EuroTravnet, the European Network for the surveillance of travel-associated diseases (https://www.istm. org/eurotravnet). Among these international travelers, we pay particular attention to several special populations facing specific risks of travel-associated diseases. Given that a large Muslim community lives in Marseille and the environs, about 2000 pilgrims travel each year to Mecca, Kingdom of Saudi Arabia (KSA) for the Hajj, one of the largest recurrent annual religious Mass Gatherings (MGs) in the

“Corresponding author.Email: philippe.gautret@club-internet.fr world [1]. In this city, there are approximately 1500 homeless persons, including 800 sleeping on city streets, park benches, and subways. Approximately 600 individuals reside temporarily at the two main municipal shelters, which have a high turnover. Most of these homeless people are migrants [2]. The Mediterranean Infection Institute works in close collaboration with the Institute of Research for Development in Senegal on various research projects, including notably the epidemiology of infections among Senegalese pilgrims traveling to participate in the Grand Magal of Touba (GMT), a large religious MG in central Senegal.

Studies aiming at investigating the circulation of infectious agents in mobile populations, notably in those participating in MG events, is one of the robust components of the research conducted at the Institute. Here, we summarize our most recent work on the molecular epidemiology of microbes and antibiotic resistance genes in special populations of travelers, including pilgrims participating in MGs, homeless people and medical students abroad.

\section{OVERALL DESIGN OF EPIDEMIOLOGICAL SURVEYS}

Since 2012, we have conducted several prospective cohort studies in Hajj pilgrims with the purpose of investigating the most frequent infections and acquisition of pathogens. Pilgrims were recruited 
through one of the private specialized travel agencies in Marseille. They were followed-up by bilingual (French and Arabic) medical doctors who travelled with the group during the Hajj. At inclusion (7-10 days before departing from France), a standardized pre-Hajj questionnaire was used to collect information about demographic characteristics and medical history. Then, 2 days before leaving the KSA, a post-Hajj questionnaire was used to collect clinical data, antibiotic intake, and information on compliance with individual preventive measures against respiratory and gastrointestinal infections. To identify the acquisition of respiratory and enteric pathogens, all pilgrims underwent nasopharyngeal and rectal swabs, upon inclusion (pre-Hajj) and just prior to leaving the KSA (postHajj). Nasopharyngeal swabs were collected by the doctors accompanying the group. Rectal swabs were self-collected by each pilgrim with a standardized procedure which was previously explained to the participants by the investigators $[3,4]$. To evaluate the interaction and dynamics of respiratory pathogens during the 2018 Hajj season, two additional respiratory swabs were collected: 5-6 days post-arrival and 12-13 days post-arrival in the KSA [5]. Samples were transported within $48 \mathrm{~h}$ of collection (or after storage at room temperature for samples collected during travel) to our laboratory in Marseille for storage at $-80^{\circ} \mathrm{C}$ until processing.

During the 2013 Hajj, a prospective cohort study was conducted among international pilgrims in collaboration with the Saudi Ministry of Health. For this purpose, upon arrival at the Jeddah airport, KSA (pre-Hajj) and after performing the Hajj, at the Mina encampment before leaving the KSA (post-Hajj), participants were invited to participate in the study (Figure 1). Pre- and post-Hajj nasal samples were collected by Saudi staff from each pilgrim, then stored in a freezer at $-80^{\circ} \mathrm{C}$ within $48 \mathrm{~h}$ of collection. The samples were subsequently transported on dry ice to our laboratory for analysis [6].

An epidemiological survey program at the GMT was started in 2017, aiming at assessing the burden of infectious disease in participants. Pilgrims from two villages - Dielmo and Ndiop, located in the Fatick region, South Senegal - were recruited (Figure 1). All pilgrims in these villages were identified by nurses in charge of primary health care centers in both villages and were invited to participate in our studies and enrolled in prospective cohort surveys. Pre-Magal swabs and questionnaires were collected 1-3 days before departing from the villages, while post-Magal samples and questionnaires were obtained 3-6 days following return from the GMT. A nurse travelled with the pilgrims to record medical issues occurring during and after the GMT. Nasopharyngeal swabs were collected by medical teams in the villages using commercial rigid cotton-tipped swab applicators. Rectal samples were collected using swab applicators from stools provided by participants in sterile containers. All samples were kept at $4^{\circ} \mathrm{C}$ before being transported to the Dakar laboratory for storage in a $-80^{\circ} \mathrm{C}$ freezer. The samples were subsequently transferred to Marseille on dry ice for processing [4].

A specific research program addressing travel-associated diseases in medical students from the Faculty of Medicine in Marseille planning to take part in an internship abroad during the summer was initiated in 2017. Students were recruited when consulting for vaccination and pre-travel advice at our institute. During this consultation, an inclusion questionnaire was used to collect demographic data, history of chronic illness, destination and intended travel dates. Pre- and post-travel kits, which contained questionnaires, sampling equipment (rigid cotton-tipped swab applicators and

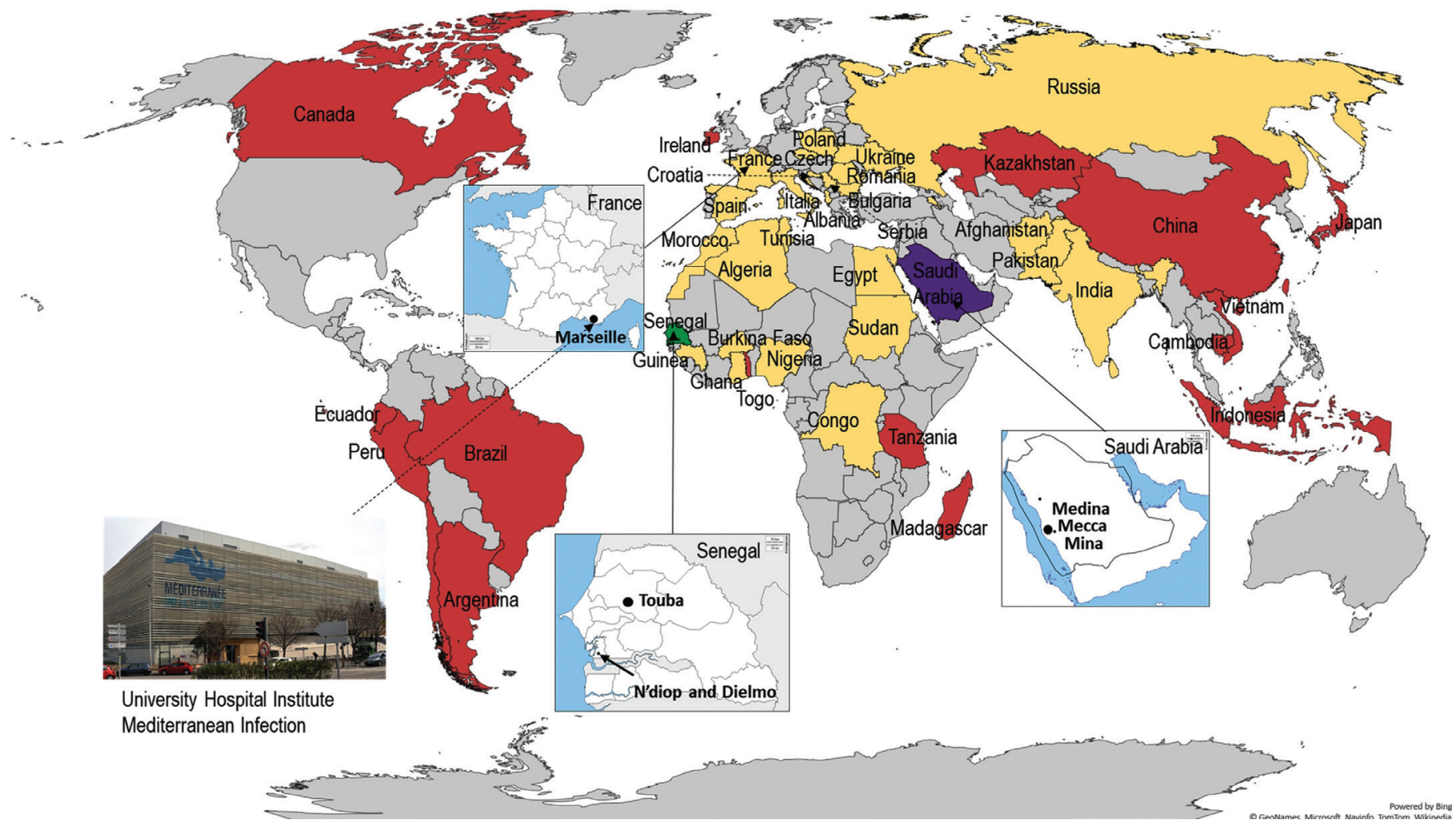

Figure 1 Countries of origin of sheltered homeless people in Marseille (yellow), countries of destination of medical students participating in an elective abroad (red), countries where a pilgrimage takes place: Hajj (purple) and Grand Magal de Touba (green). 
transport media) and an instructional document for self-sampling were provided to participants. Investigators instructed them how to self-collect respiratory, rectal and vaginal samples. The exact place of the internship, activities during their stay (missions, tourism or travel in the host country or other countries during the internship period), accommodation conditions, contact with children or animals, clinical symptoms and treatment during their stay were also documented by a post-travel questionnaire. The self-samples were collected during the week before travel (pre-travel swabs) and during the week following return to France (post-travel swabs) and stored at $-80^{\circ} \mathrm{C}$ until processing [7-9]. The countries where electives took place are presented in Figure 1.

Since 2000, studies conducted among homeless individuals have been performed in two homeless shelters or at the hospital. Cross sectional 1-day surveys have been organized by medical teams of our institute. At inclusion, adult homeless people were asked to complete questionnaires, including information on demographics, personal history, substance use, preventive measures and clinical presentation. The countries of origin of homeless people sheltered in Marseille are shown in Figure 1. Body lice were removed from the body and clothes of infested homeless persons, then were transferred to sterile plastic tubes and subsequently processed for molecular analysis $[10,11]$. Skin swabs were collected and resuspended in Hank's balanced salt solution before processing for molecular technique [12]. Nasal and pharyngeal swabs were collected by medical staff from each participant and stored at $-80^{\circ} \mathrm{C}$ before PCR testing for respiratory pathogens (other than Mycobacterium tuberculosis) [13]. For M. tuberculosis detection, sputum samples were systematically collected from each participant in a sterile vial [14]. Recently, for screening of Severe Acute Respiratory Syndrome Coronavirus 2 (SARS-CoV-2), a nasal swab was self-collected by each homeless person using a standardized procedure that was previously explained to the participants by the investigators $[15,16]$. For gastrointestinal pathogen carriage, rectal [17] or stool samples were systematically collected on transport media [18]. Molecular prevalence surveys of the Antibiotic-resistance encoding Genes (ARGs) were performed on respiratory or rectal samples and compared to that of a control group (defined as the non-homeless group), including administrative staff, physicians, nurses, medical students and PhD students from our institute [19].

In addition, molecular epidemiological investigations were performed among hospitalized homeless persons (in emergency departments or infectious disease units) to diagnose louse-borne, respiratory or gastrointestinal diseases $[20,21]$.

\section{OVERALL DESIGN OF THE MICROBIOLOGICAL METHOD}

Common pathogens were detected by real-time PCR (qPCR). The most frequent pathogens, including bacteria, viruses and parasites, were selected according to the literature. Studies on the carriage of multi-drug resistant bacteria were performed using culture methods. ARG were identified in isolates by qPCR, conventional PCR and sequencing. ARG detection was also performed directly on respiratory and rectal swabs using molecular methods. In some studies, DNA pooling was performed to reduce the cost of molecular reactions. Tables 1 and 2 show the target pathogens and molecular methods for each study.

\section{RESULTS}

\subsection{Hajj and Grand Magal Pilgrims}

We evidenced significant acquisition of respiratory pathogens by comparing the prevalence of pathogens in pre- and post-travel samples. The overall prevalence of viruses and bacteria increased significantly from $7.4 \%$ and $15.4 \%$ before the Hajj to $45.4 \%$ and $31.0 \%$ after the Hajj, respectively [6]. More specifically, we evidenced a significant acquisition of Staphylococcus aureus (7.5-14.5\%), Haemophilus influenzae (11.4-33.3\%), Klebsiella pneumoniae (3.9-21.7\%), Moraxella catarrhalis (33.1\%), Streptococcus pneumoniae (9.8-18.5\%), rhinovirus (14.9-34.1\%), common human coronaviruses (8.3-9.2\%) and influenza viruses $(3.2-3.7 \%)[5,6,22,23]$. These results were consistently observed over time. Despite a high proportion of respiratory symptoms, including Influenza-like Illness (ILI) during the Hajj, the Middle East respiratory coronavirus was never isolated from pilgrims returning to Marseille and from those returning from other places $[6,24]$. Looking at the interactions between pathogens, we observed that the carriage of rhinovirus and the carriage of $S$. aureus were positively associated. This positive interaction was also found between $H$. influenzae and $M$. catarrhalis [5]. The $H$. influenzae genotypes acquired in Saudi Arabia were completely different from those present before travel. We also observed a lack of clonality and a high biodiversity of $H$. influenzae among French Hajj pilgrims [22].

Recently, we studied the association between microbiological carriage and clinical symptoms in Hajj pilgrims and the role of preventive measures. Carriage of $K$. pneumoniae, $M$. catarrhalis$S$. aureus and $H$. influenzae-rhinovirus co-infections was significantly associated with the occurrence of Low Respiratory Tract Infection (LRTI) symptoms [5,22].

In addition, vaccination against invasive pneumococcal diseases and influenza was associated with a decrease in the acquisition of S. pneumoniae and in the prevalence of ILI symptoms [23]. Acquisition of rhinovirus was higher among pilgrims who reported using face masks. The use of disposable handkerchiefs was associated with a lower acquisition of $S$. aureus [23].

With regard to gastrointestinal pathogens, we evidenced a significant acquisition by Hajj pilgrims of Escherichia coli, with EAEC, EPEC and EHEC the most frequent [3].

In addition, we found that Hajj pilgrims acquired gastrointestinal extended-spectrum $\beta$-lactamase-producing and colistin-resistant Salmonella enterica, as well as $m c r-1$ colistin-resistant genes of K. pneumoniae and E. coli [26-28]. We also observed an acquisition of respiratory and gastrointestinal carbapenemase-encoding genes [29]. CTX-M gene acquisition was positively associated with diarrhea and dyspnea. By contrast, use of macrolides decreased the acquisition of CTX-M genes [30].

A recent study addressing the epidemiology of infectious diseases at the GMT also demonstrated a high acquisition rate of $S$. pneumoniae and $H$. influenzae, rhinoviruses, and common coronaviruses by pilgrims following participation in the event [4], while Neisseria meningitidis was never detected [31]. Acquisition of gastrointestinal pathogens was also high, with EPEC, EAEC and EHEC the most frequent [4]. 


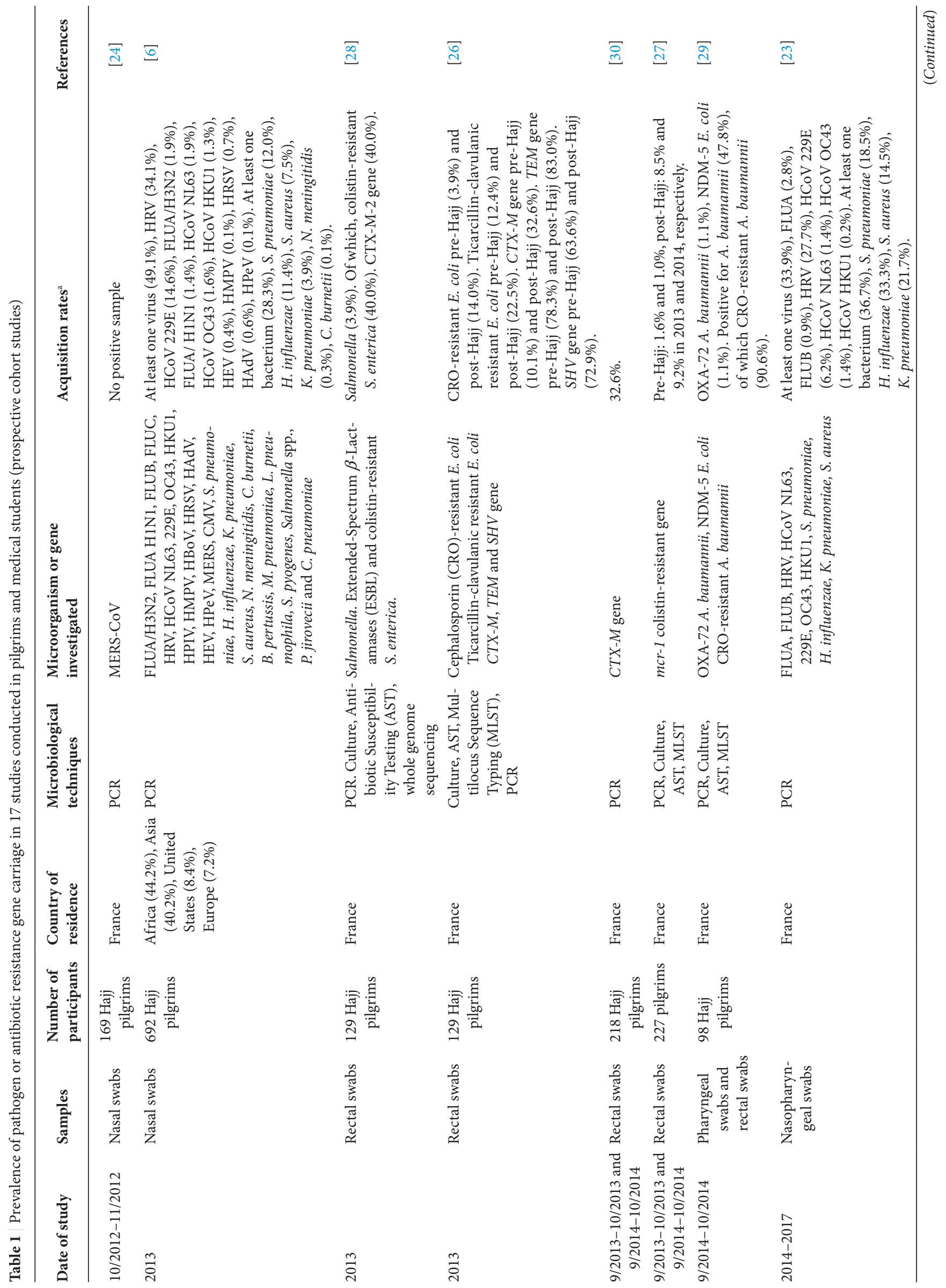



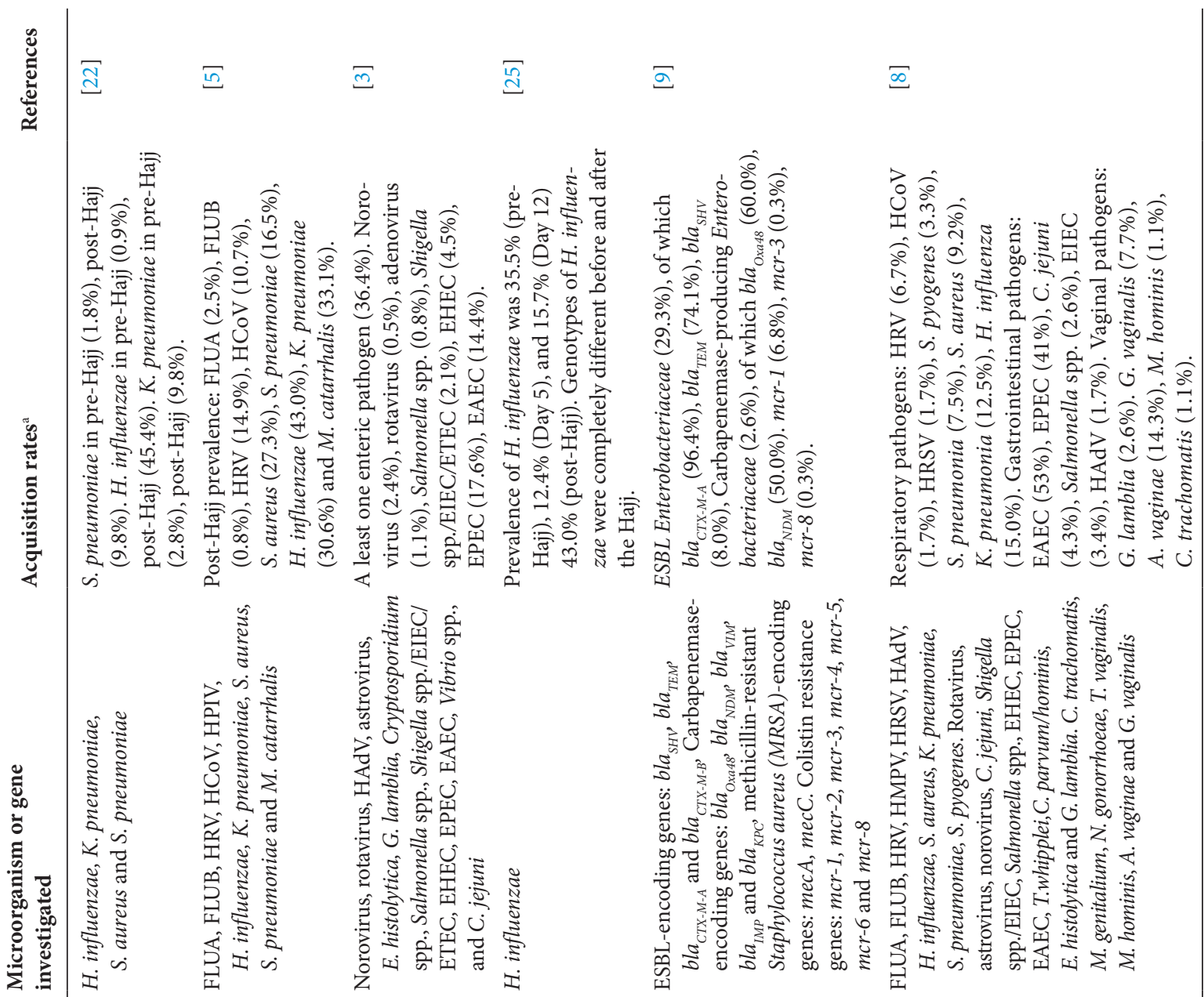

岁

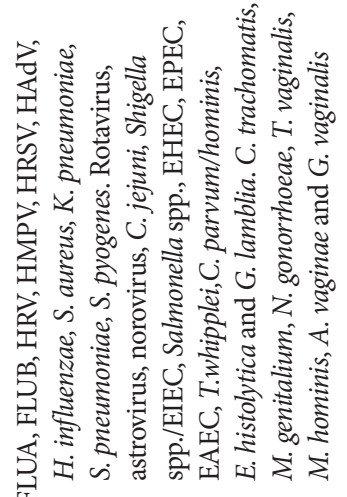

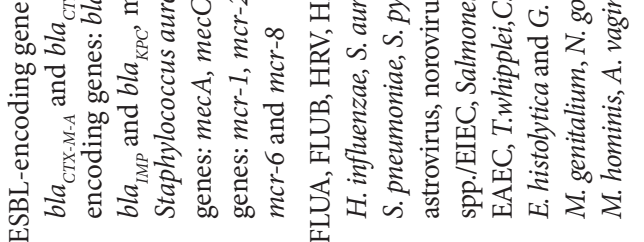

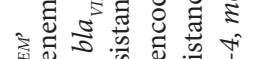

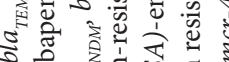

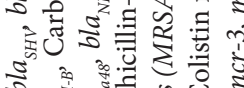

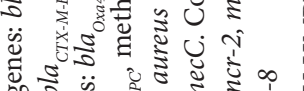

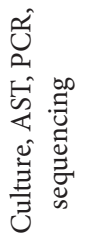

્ㅗㅇ

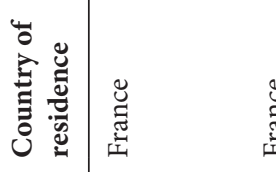<smiles>[CH]1CCC1</smiles><smiles>[CH]1[CH]C=C1</smiles><smiles></smiles>

藏<smiles>[CH][CH]</smiles>

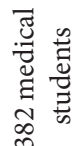

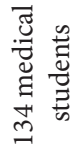

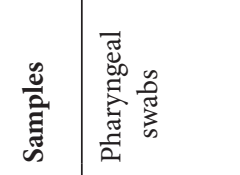

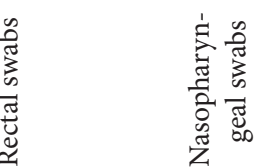
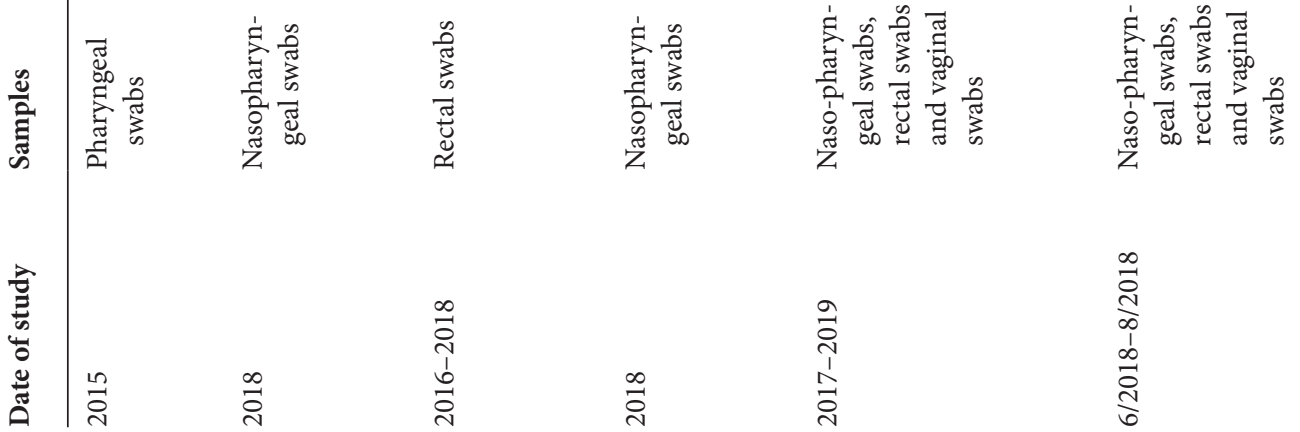

$\stackrel{\infty}{\stackrel{2}{*}}$

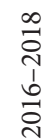

$\stackrel{\infty}{\stackrel{2}{1}}$

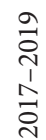

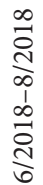




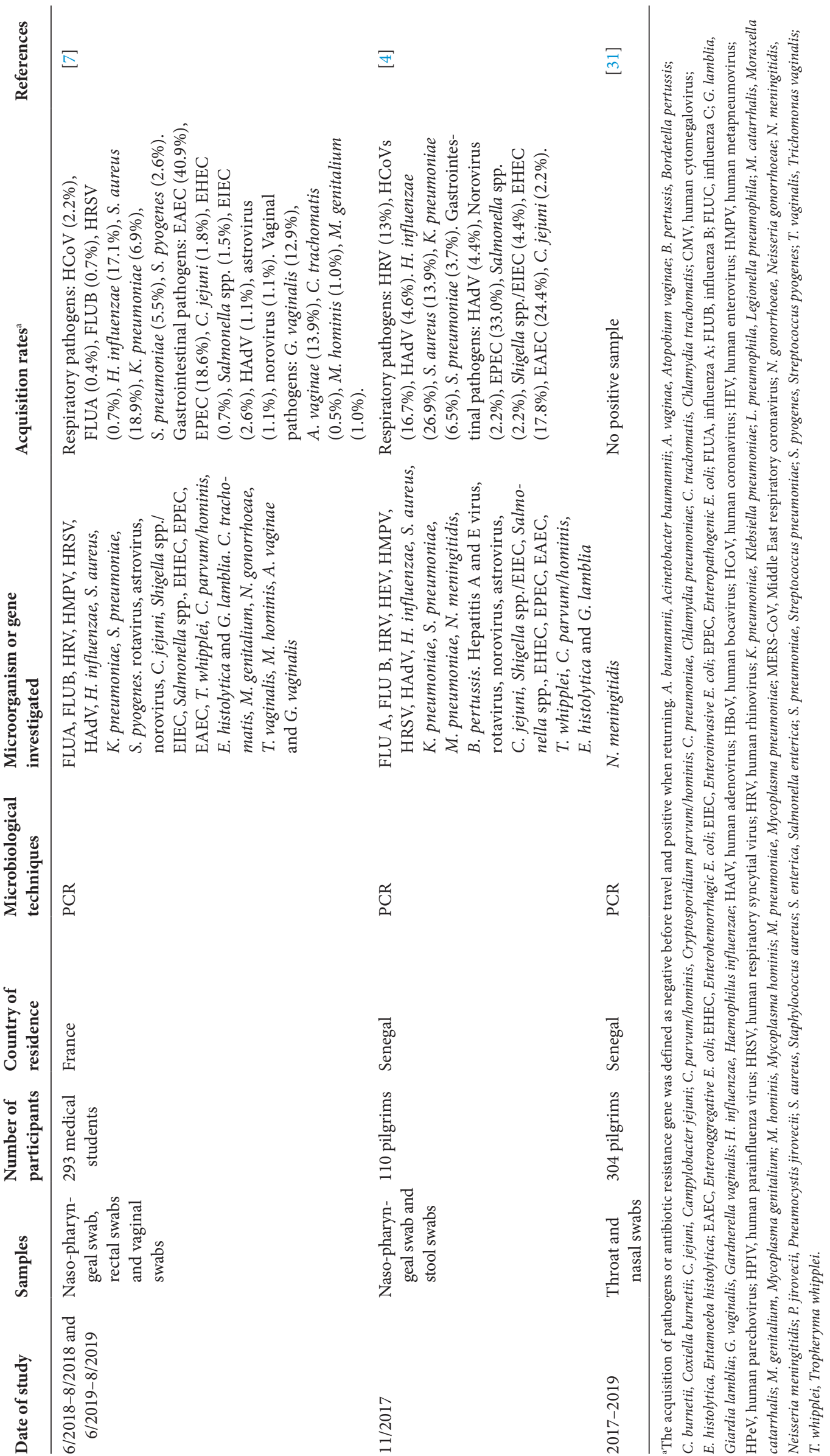




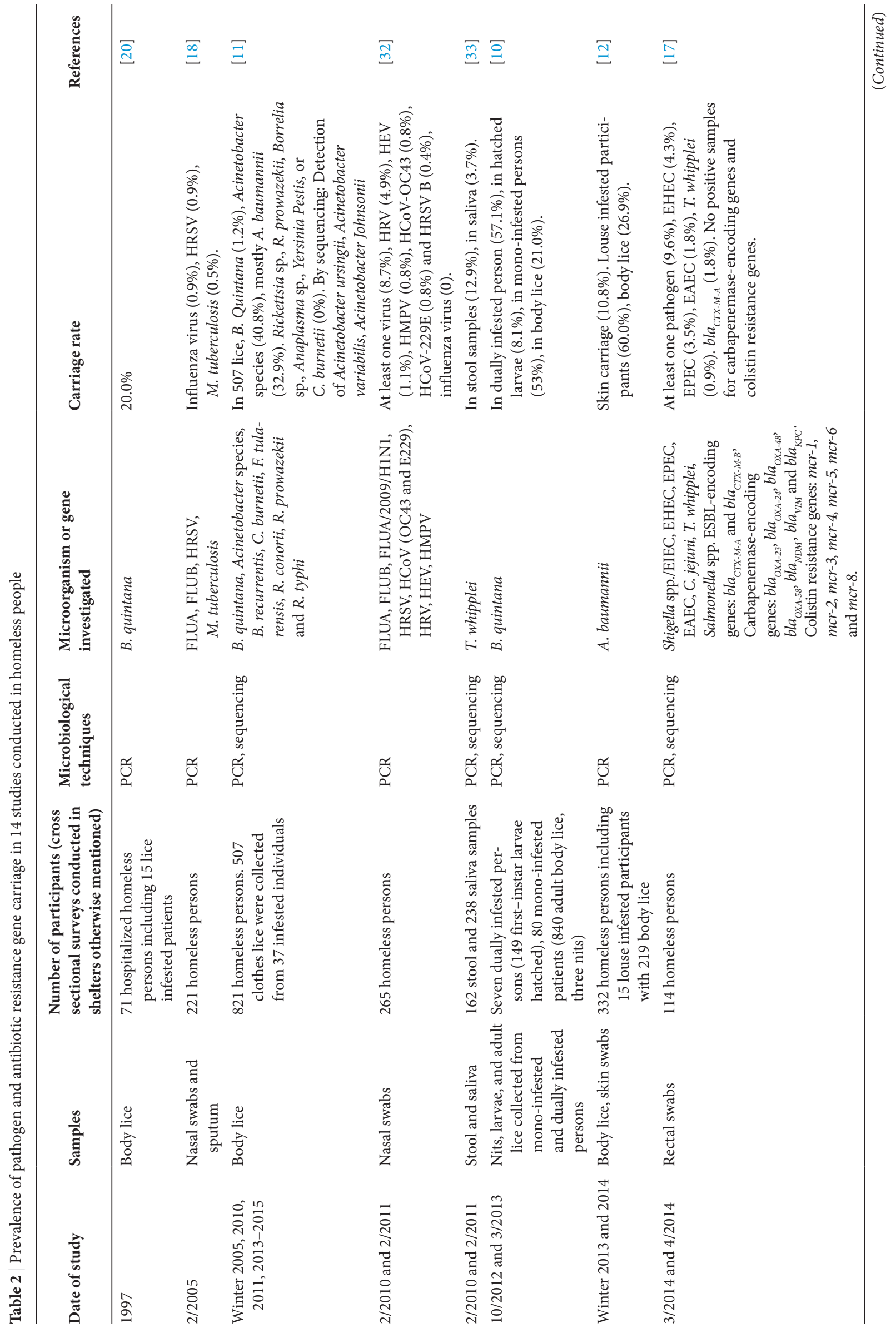




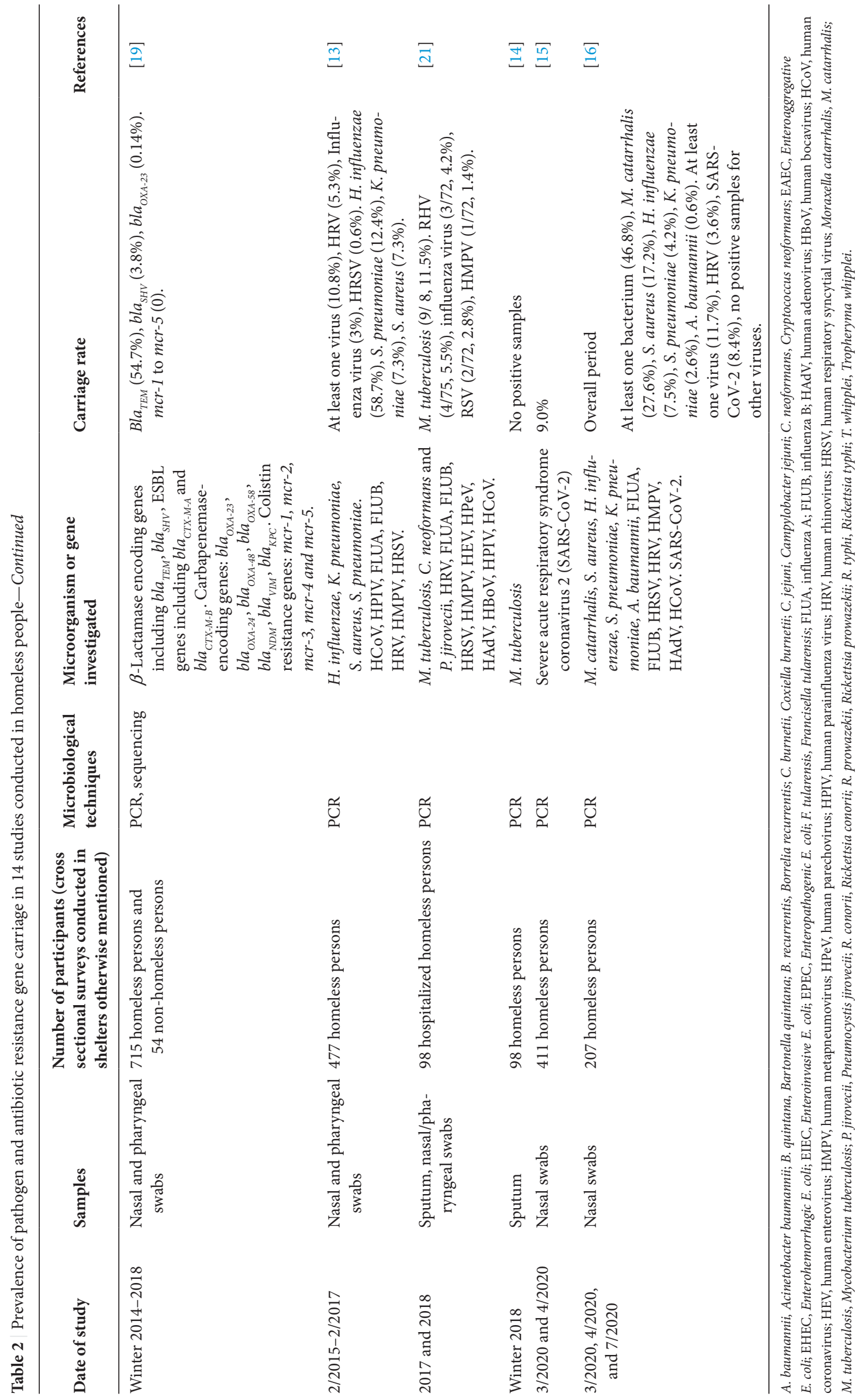




\subsection{Medical Students}

Medical students reported frequent gastrointestinal (74\%), respiratory (39\%) and vaginal (5\%) symptoms [8]. The overall acquisition rate of respiratory bacteria was $41 \%$, with the highest rates observed for S. aureus (19\%) and H. influenzae (17\%), while the overall rate of respiratory virus acquisition was $18 \%$, rhinovirus being predominant (15\%) [7]. Acquisition of enteric bacteria was high (49\%), with EAEC (41\%) and EPEC (19\%) the most frequent $[7,8]$. Female students also acquired Atopobium vaginae (14\%) and Gardnerella vaginalis (13\%) [7].

Acquisition of S. pneumoniae was low (5.5\%) but students presenting respiratory symptoms were three times more likely to acquire S. pneumoniae during travel [7].

Recently, the acquisition of antibiotic-resistant bacteria, including extended-spectrum $\beta$-lactamase-producing Enterobacteriaceae and carbapenemase-producing Enterobacteriaceae, has been evidenced in French medical students during an elective abroad, notably when travelling to South East Asia [9]. In addition, acquisition of colistin resistance genes has been observed.

\subsection{Homeless People}

Studies on body lice conducted among infested homeless persons have identified a high prevalence of louse-borne pathogens (including Bartonella quintana), but with a decreasing trend from 2000 to 2018 [10,11,20]. The presence of Acinetobacter baumannii DNA was also demonstrated in human body lice and skin samples, with a high prevalence $[11,12]$.

The snapshot interventions demonstrated high rates of respiratory virus (notably rhinovirus and influenza viruses) [32], and bacteria (notably $H$. influenzae and S. pneumoniae) carriage [13]. A strong association between $S$. pneumoniae or respiratory virus carriage (including influenza viruses) and respiratory symptoms was also found with an increased prevalence of respiratory signs [13]. Overall, homeless people carrying at least one virus were 2.5 times more likely to present with cough or rhinorrhea and seven times more likely to have a sore throat. Carriage of S. pneumoniae was associated with a 2.5 times increased frequency of cough [13]. Using qPCR, Mycobacteria tuberculosis was detected with a high prevalence among hospitalized homeless individuals [21], but low prevalence among sheltered homeless persons, through cross-sectional surveys [14,18]. Recently, we started a new research project on SARS-CoV-2 among sheltered homeless persons in Marseille, France, and observed a prevalence rate of $9.0 \%$ [15]. SARS-CoV-2 carriage correlated with symptoms, however $51 \%$ of patients testing positive were asymptomatic. Being less than 34 years and being housed in one specific shelter were independent factors associated with SARS-CoV-2 positivity (rates of $11.4 \%$ and $20.6 \%$, respectively) [15]. Repeated sampling in the same population conducted over the year 2020 showed a significant decrease of SARS-CoV-2 positivity rates following implementation of measures to mitigate the risk of transmission at shelters. These measures also impacted bacterial carriage [16].

We also evidenced the presence of digestive pathogen carriage in rectal, stool or saliva samples, such as E. coli pathotypes [17] and Tropheryma whipplei [33].
A study directly assessing resistance gene carriage rates in nasal/ pharyngeal samples reported a lower proportion of $\beta$-lactamase-encoding gene carriage, including extended-spectrum $\beta$-lactamases, especially those belonging to the CTX-M family, carbapenem-hydrolyzing $\beta$-lactamases, among sheltered homeless individuals in Marseille as compared to controls [19]. We also observed a lack of $m c r-1, m c r-2, m c r-3, m c r-4$ and $m c r-5$ genes [19]. This work demonstrated that the type of housing (shelter A versus B) and smoking were significantly associated with antibiotic resistance gene carriage among homeless persons.

\section{DISCUSSION AND CONCLUSION}

Travel medicine has long been focused on diseases affecting tourist travelers, business travelers and expatriates. The increasing migration flow from low- to high-income countries in recent decades has led travel medicine specialists to expand their field of interest to migrant health and travel-associated diseases in VFRs [34]. More recently, emerging fields have appeared in travel medicine because of a growing proportion of travelers with specific reasons for travel, including, among others, medical tourism [35], participation in international mass gatherings [36], social exclusion due to homelessness [37] or participation in an elective abroad [38]. Results from large multicentric surveys conducted by GeoSentinel and EuroTravNet on ill international travelers have clearly underlined the critical role of the traveler's profile (including notably their reason for travel) in the clinical pattern of travel-associated diseases $[39,40]$ Nevertheless, the major limitation of these network studies is the lack of a denominator, precluding calculation of the proportion of ill travelers among all travelers [41]. This can be achieved by conducting prospective cohort surveys or periodic cross-sectional surveys. In the prospective cohort surveys that we conducted on international travelers (Hajj pilgrims or medical students) and on domestic travelers (Grand Magal pilgrims), each traveler is their own control when assessing their health status or pathogen carriage before and after exposure to a potential risk factor (international travel and/or participation in a specific event such as a religious MG or a medical elective). One-day cross-sectional surveys conducted in homeless people (snapshot surveys) also evaluate the prevalence of disease and pathogen carriage in the population investigated. However, to formally associate diseases and pathogen carriage with a potential risk factor (being homeless), a control population (non-homeless people) must be investigated at the same time. In so doing, we identified infectious diseases and the main infectious pathogens linked to travel in certain specific populations of international travelers and homeless migrant people. Such results, together with those obtained through international surveillance networks, allow better description of the epidemiology of travel-associated infectious disease. S. aureus, $H$. influenzae, K. pneumoniae, M. catarrhalis, S. pneumoniae, rhinovirus, common human coronaviruses and influenza viruses were the respiratory pathogens the most frequently acquired at the Hajj while $S$. pneumoniae, $H$. influenzae, rhinoviruses, and common coronaviruses were the pathogens most frequently acquired at the GMT. With regard to gastrointestinal pathogens, EPEC, EAEC and EHEC were the pathogen most frequently acquired by Hajj and GMT pilgrims. In medical students returned from elective abroad, the most frequently acquired respiratory pathogens included $S$. aureus, $H$. influenzae, and rhinovirus and 
the most frequently acquired enteric bacteria included EAEC and EPEC. In homeless population, our results demonstrated high rates of rhinovirus and influenza viruses, $H$. influenzae and S. pneumoniae carriage. Interestingly, high prevalence of $B$. quintana and A. baumannii were observed in this population. The role of several risk factors was demonstrated, allowing identification of individuals at increased risk of disease or pathogen carriage on which to base targeted preventive and therapeutic measures. In pilgrims, vaccination against invasive pneumococcal diseases and influenza was associated with a decrease in the acquisition of S. pneumoniae and prevalence of influenza-like-illness, respectively [5,23]. The carriage of $S$. pneumoniae was higher among pilgrims with chronic respiratory disease [5]. In addition, among the pathogens most frequently acquired by pilgrims, three accounted for vaccinepreventable diseases, including influenza, S. pneumoniae and $H$. influenzae infections [6]. Vaccination against seasonal influenza of all target individuals attending the Hajj should be promoted. Vaccination against $S$. pneumoniae infection should be considered in pilgrims with medical risk factors. We also evidenced the role of K. pneumoniae and M. catarrhalis-S. aureus association and $H$. influenzae-rhinovirus association in the occurrence of possible LRTI symptoms. This reinforces the need for antibiotic use in case of LRTI symptoms [5]. In addition, the use of face masks, the reinforcement of hand hygiene and the use of disposable handkerchief should still be recommended for pilgrims to reduce respiratory symptoms and acquisition of respiratory pathogens $[22,23]$. To prevent and reduce the rate of multidrug resitant (MDR) bacterial transmission in Hajj pilgrims, personal hygiene including hand hygiene also should be taught and monitored, together to rationalization of antibiotic use [29,30]. In homeless persons, we found a strong association between viruses or S. pneumoniae carriage and RTI symptoms [13]. This suggests the need for vaccination against influenza and $S$. pneumoniae infections in such population $[13,18]$. Additionally, we suggest using diagnostic set kits for the most frequent infectious diseases among homeless people at hospital admission, including respiratory virus multiplex PCR testing [21]. We also recommend measures to mitigate the risk of transmission of SARS-CoV-2 in homeless person including staying at housing facility, avoiding gathering of persons, keeping distance from others, wearing a mask, washing hands with soap and water frequently and for at least $20 \mathrm{~s}$, practicing cough etiquette, and avoiding touching the eyes, nose, or mouth with unwashed hands $[15,16]$. To prevent skin infections and body-lice infestation, we recommended improvement of personal clothing, and room hygiene and application of insecticide, laundry, and ivermectin treatment when infested [11,12]. Screening for latent and active TB and parasitological infections in newly arrived migrants at homeless shelters, establishing health services and management systems for respiratory chronic diseases and regular clinical follow-ups for infected homeless persons with TB are also advisable $[11,14,18,21]$. The acquisition of ESBL-encoding and colistin resistance genes by medical students during travel abroad is frequent [9]. Because of a theoretical risk of community and hospital spread, medical students as other healthcare should practice reinforced standard precautions (hand disinfection with an alcoholbased solution) after return from areas with a high prevalence of MDR bacterial carriage.

A major strength of our work is that the study design allowed working with relatively homogeneous populations of individuals.
Hajj pilgrims were recruited from a single travel agency, traveled together, stayed at the same hotels in Mecca and Medina and the same tents in Mina, and participated in rituals together. GMT pilgrims were recruited from two closed villages in Senegal, traveled together to Touba, stayed in the same housing facilities and participated in rituals at the same time. Medical students were recruited mostly through a single medical student association organizing electives abroad and underwent the same pre-travel evaluation, vaccinations and counseling at our travel clinic. Homeless people were recruited from two large shelters in Marseille with very similar housing conditions. High participation rates of participants were ensured by working closely with key persons, including the accompanying Mutawafs (spiritual guide) for Hajj pilgrims, the customary chief in Senegal villages, presidents of medical student associations in Marseille University and directors of homeless shelters in Marseille. Follow-up by mobile medical teams participating in the pilgrimages or by the medical students themselves, and close collaboration with homeless shelter medical teams ensured obtaining reliable clinical data and good quality samples.

In addition, using a similar epidemiological study design with standardized questionnaires and molecular assays allows comparison of different populations of travelers. Strong similarities were observed between the Hajj and GMT pilgrimages, although they occur in very different settings and involve distinct populations of pilgrims. At both MGs, a high prevalence of symptoms of respiratory tract infection with acquisition of cosmopolitan respiratory bacteria and viruses was observed, suggesting that the MG context overcomes geographical, climatologic and demographic factors. Similarly, Hajj and GMT pilgrims exhibited high acquisition rates of EPEC, EAEC and EHEC. In conclusion, these studies allow both identification of emerging threats such as the acquisition of drug resistant bacteria at the Hajj, and better understanding of the relationship between pathogen carriage and clinical symptoms on which to base preventive and therapeutic strategies.

\section{CONFLICTS OF INTEREST}

The authors declare they have no conflicts of interest.

\section{AUTHORS' CONTRIBUTION}

All authors contributed equally to drafting the manuscript and reviewed and approved the final version of the manuscript. TLD coordinated the work. PG conceptualized and supervised the work.

\section{FUNDING}

No financial support was provided.

\section{REFERENCES}

[1] Gautret P, Bauge M, Simon F, Benkouiten S, Parola P, Brouqui P. Travel reported by pilgrims from Marseille, France before and after the 2010 Hajj. J Travel Med 2012;19;130-2. 
[2] Ly TDA, Touré Y, Calloix C, Badiaga S, Raoult D, Tissot-Dupont $\mathrm{H}$, et al. Changing demographics and prevalence of body lice among homeless persons, Marseille, France. Emerg Infect Dis 2017;23;1894-7.

[3] Hoang VT, Dao TL, Ly TDA, Sow D, Belhouchat K, Larbi Chaht $\mathrm{K}$, et al. Gastrointestinal symptoms and the acquisition of enteric pathogens in Hajj pilgrims: a 3-year prospective cohort study. Eur J Clin Microbiol Infect Dis 2021;40;315-23.

[4] Hoang VT, Goumballa N, Dao TL, Ly TDA, Ninove L, Ranque S, et al. Respiratory and gastrointestinal infections at the 2017 Grand Magal de Touba, Senegal: a prospective cohort survey. Travel Med Infect Dis 2019;32;101410.

[5] Hoang VT, Dao TL, Ly TDA, Belhouchat K, Chaht KL, Gaudart J, et al. The dynamics and interactions of respiratory pathogen carriage among French pilgrims during the 2018 Hajj. Emerg Microbes Infect 2019;8;1701-10.

[6] Memish ZA, Assiri A, Turkestani A, Yezli S, Al Masri M, Charrel $\mathrm{R}$, et al. Mass gathering and globalization of respiratory pathogens during the 2013 Hajj. Clin Microbiol Infect 2015;21; 571.e1-571.e8.

[7] Dao TL, Canard N, Hoang VT, Ly TDA, Drali T, Ninove L, et al. Risk factors for symptoms of infection and microbial carriage among French medical students abroad. Int J Infect Dis 2020; 100;104-11.

[8] Dao TL, Hoang VT, Ly TDA, Magmoun A, Canard N, Drali T, et al. Infectious disease symptoms and microbial carriage among French medical students travelling abroad: a prospective study. Travel Med Infect Dis 2020;34;101548.

[9] Dao TL, Hoang VT, Magmoun A, Ly TDA, Baron SA, Hadjadj $\mathrm{L}$, et al. Acquisition of multidrug-resistant bacteria and colistin resistance genes in French medical students on internships abroad. Travel Med Infect Dis 2021;39;101940.

[10] Drali R, Sangaré AK, Boutellis A, Angelakis E, Veracx A, Socolovschi C, et al. Bartonella quintana in body lice from scalp hair of homeless persons, France. Emerg Infect Dis 2014;20;907-8.

[11] Ly TDA, Amanzougaghene N, Hoang VT, Dao TL, Louni M, Mediannikov O, et al. Molecular evidence of bacteria in clothes lice collected from homeless people living in shelters in Marseille. Vector Borne Zoonotic Dis 2020;20;872-4.

[12] Ly TDA, Kerbaj J, Edouard S, Hoang VT, Louni M, Dao TL, et al. The presence of Acinetobacter baumannii DNA on the skin of homeless people and its relationship with body lice infestation. Front Cell Infect Microbiol 2019;9;86.

[13] Ly TDA, Edouard S, Badiaga S, Tissot-Dupont H, Hoang VT, Pommier de Santi V, et al. Epidemiology of respiratory pathogen carriage in the homeless population within two shelters in Marseille, France, 2015-2017: cross sectional 1-day surveys. Clin Microbiol Infect 2019;25;249.e1-249.e6.

[14] Ly TDA, Holi-Jamovski F, Hoang VT, Dao TL, Drancourt M, Gautret P. Preliminary feasibility study of questionnaire-based active pulmonary tuberculosis screening in Marseille sheltered homeless people, winter 2018. J Epidemiol Glob Health 2019;9;143-5.

[15] Ly TDA, Nguyen NN, Hoang VT, Goumballa N, Louni M, Canard N, et al. Screening of SARS-CoV-2 among homeless people, asylum-seekers and other people living in precarious conditions in Marseille, France, March-April 2020. Int J Infect Dis 2021;105;1-6.

[16] Ly TDA, Hoang VT, Goumballa N, Louni M, Canard N, Dao $\mathrm{TL}$, et al. Variations in respiratory pathogen carriage among a homeless population in a shelter for men in Marseille, France,
March-July 2020: cross-sectional 1-day surveys. Eur J Clin Microbiol Infect Dis 2021;1-4 [Online ahead of print].

[17] Ly TDA, Hadjadj L, Hoang VT, Goumbala N, Dao TL, Badiaga $\mathrm{S}$, et al. Enteric pathogenic bacteria and resistance gene carriage in the sheltered homeless population in Marseille, France. Acta Microbiol Immunol Hung 2021;68;7-13.

[18] Badiaga S, Richet H, Azas P, Zandotti C, Rey F, Charrel R, et al. Contribution of a shelter-based survey for screening respiratory diseases in the homeless. Eur J Public Health 2009;19;157-60.

[19] Ly TDA, Hadjadj L, Hoang VT, Louni M, Dao TL, Badiaga S, et al. Low prevalence of resistance genes in sheltered homeless population in Marseille, France, 2014-2018. Infect Drug Resist 2019;12;1139-51.

[20] Brouqui P, Lascola B, Roux V, Raoult D. Chronic Bartonella quintana bacteremia in homeless patients. $\mathrm{N}$ Engl J Med $1999 ; 340 ; 184-9$.

[21] Ly TDA, Dao TL, Hoang VT, Braunstein D, Brouqui P, Lagier JC, et al. Pattern of infections in French and migrant homeless hospitalised at Marseille infectious disease units, France: a retrospective study, 2017-2018. Travel Med Infect Dis 2020;36;101768.

[22] Hoang VT, Meftah M, Ly TDA, Drali T, Yezli S, Alotaibi B, et al. Bacterial respiratory carriage in French Hajj pilgrims and the effect of pneumococcal vaccine and other individual preventive measures: a prospective cohort survey. Travel Med Infect Dis 2019;31;101343.

[23] Hoang VT, Ali-Salem S, Belhouchat K, Meftah M, Sow D, Dao TL, et al. Respiratory tract infections among French Hajj pilgrims from 2014 to 2017. Sci Rep 2019;9;17771.

[24] Gautret P, Charrel R, Belhouchat K, Drali T, Benkouiten S, Nougairede A, et al. Lack of nasal carriage of novel corona virus (HCoV-EMC) in French Hajj pilgrims returning from the Hajj 2012, despite a high rate of respiratory symptoms. Clin Microbiol Infect 2013;19;E315-E17.

[25] Hoang VT, Dao TL, Ly TDA, Belhouchat K, Larbi Chaht K, Yezli $\mathrm{S}$, et al. Dynamics and genetic diversity of Haemophilus influenzae carriage among French pilgrims during the 2018 Hajj: a prospective cohort survey. Travel Med Infect Dis 2020;38;101883.

[26] Leangapichart T, Dia NM, Olaitan AO, Gautret P, Brouqui P, Rolain JM. Acquisition of extended-spectrum $\beta$-lactamases by Escherichia coli and Klebsiella pneumoniae in gut microbiota of pilgrims during the Hajj pilgrimage of 2013. Antimicrob Agents Chemother 2016;60;3222-6.

[27] Leangapichart T, Gautret P, Brouqui P, Memish ZA, Raoult D, Rolain JM. Acquisition of $m c r-1$ plasmid-mediated colistin resistance in Escherichia coli and Klebsiella pneumoniae during Hajj 2013 and 2014. Antimicrob Agents Chemother 2016;60;6998-9.

[28] Olaitan AO, Dia NM, Gautret P, Benkouiten S, Belhouchat K, Drali T, et al. Acquisition of extended-spectrum cephalosporinand colistin-resistant Salmonella enterica subsp. enterica serotype Newport by pilgrims during Hajj. Int J Antimicrob Agents $2015 ; 45 ; 600-4$.

[29] Leangapichart T, Gautret P, Griffiths K, Belhouchat K, Memish Z, Raoult D, et al. Acquisition of a high diversity of bacteria during the Hajj Pilgrimage, including Acinetobacter baumannii with $b l a_{\mathrm{OXA}-72}$ and Escherichia coli with $b l a_{\mathrm{NDM}-5}$ carbapenemase genes. Antimicrob Agents Chemother 2016;60;5942-8.

[30] Leangapichart T, Tissot-Dupont H, Raoult D, Memish ZA, Rolain JM, Gautret P. Risk factors for acquisition of CTX-M genes in pilgrims during Hajj 2013 and 2014. J Antimicrob Chemother 2017;72;2627-35.

[31] Goumballa N, Hoang VT, Perieres L, Parola P, Sokhna C, Gautret P. Lack of Neisseria meningitidis among pilgrims during the 2017, 
2018 and 2019 Grand Magal of Touba, Senegal. Clin Microbiol Infect 2020;26;1697-98.

[32] Thiberville SD, Salez N, Benkouiten S, Badiaga S, Charrel R, Brouqui P. Respiratory viruses within homeless shelters in Marseille, France. BMC Res Notes 2014;7;81.

[33] Keita AK, Brouqui P, Badiaga S, Benkouiten S, Ratmanov P, Raoult D, et al. Tropheryma whipplei prevalence strongly suggests human transmission in homeless shelters. Int J Infect Dis 2013; 17;e67-e8.

[34] Schlagenhauf P, Santos-O'Connor F, Parola P. The practice of travel medicine in Europe. Clin Microbiol Infect 2010;16;203-8.

[35] Lunt N, Horsfall D, Hanefeld J. Medical tourism: a snapshot of evidence on treatment abroad. Maturitas 2016;88;37-44.

[36] Memish ZA, Steffen R, White P, Dar O, Azhar EI, Sharma A, et al. Mass gatherings medicine: public health issues arising from mass gathering religious and sporting events. Lancet 2019;393; 2073-84.
[37] Raoult D, Foucault C, Brouqui P. Infections in the homeless. Lancet Infect Dis 2001;1;77-84.

[38] Johnston N, Sandys N, Geoghegan R, O’Donovan D, Flaherty G. Protecting the health of medical students on international electives in low-resource settings. J Travel Med 2018;25;tax092.

[39] Harvey K, Esposito DH, Han P, Kozarsky P, Freedman DO, Plier DA, et al. Surveillance for travel-related disease-GeoSentinel Surveillance System, United States, 1997-2011. MMWR Surveill Summ 2013;62;1-23.

[40] Schlagenhauf P, Weld L, Goorhuis A, Gautret P, Weber R, von Sonnenburg F, et al. Travel-associated infection presenting in Europe (2008-12): an analysis of EuroTravNet longitudinal, surveillance data, and evaluation of the effect of the pre-travel consultation. Lancet Infect Dis 2015;15;55-64.

[41] Gautret P, Leder K, Field V, Kain KC, Hamer DH, Libman M. GeoSentinel surveillance of travel-associated infections: what lies in the future?. Travel Med Infect Dis 2020;36;101600. 